\title{
First testing experiments with measurement of pool boiling heat transfer coefficient on a new apparatus
}

\author{
Viktor Vajc ${ }^{1, *}$ and Martin Dostál ${ }^{1, * *}$ \\ ${ }^{1}$ Department of Process Engineering, Faculty of Mechanical Engineering, Czech Technical University, 16607 Prague, Czech Republic
}

\begin{abstract}
We have designed a simple apparatus for measurement of heat transfer during pool boiling in order to find or create suitable correlations for heat-transfer coefficient, which could be used for various liquids and conditions. We have run several testing experiments with tap and deionized water. This contribution presents proceedings and the first results of these experiments as well as comparison of these results with some published and verified correlations.
\end{abstract}

\section{Introduction}

Pool boiling is a process, which is commonly used in various industries, e.g., energetics, petroleum refining, petrochemical and chemical industry, distillation plants, process-gas and air-separation industries, food and beverage production, refrigeration industry, etc. Heat exchangers are apparatuses in which boiling typically occurs. If they are used to generate vapor for a distillation column, then they are called reboilers. Otherwise, when used for other purposes, they are often labeled as vaporizers. There is no principal difference between reboilers and vaporizers.

Nucleate boiling is one and the most common regime of boiling characterized by nucleation of new bubbles. Bubbles emerge on heating surface from nucleation embryos, which are entrapped in cavities, i.e., irregularities of a heating surface. Nucleation of new bubbles occurs in periodic cycles.

Pool boiling is a special type of boiling during which any movement of liquid phase related to the heating surface is caused only by emerging bubbles. In other words there is no external factor responsible for liquid movement during pool boiling.

\section{Correlations for heat transfer coefficient}

There are a lot of heat transfer correlations, which can be used to estimate heat-transfer coefficient $\alpha$ during saturated nucleate pool boiling. They are based on different (often contradictory) assumptions and theoretical approaches. A list of some of these correlations can be found in Vajc [1]. Several of these correlations are considered as verified and are recommended by worldwide community of scientists and engineers. We will briefly describe five

\footnotetext{
*e-mail: viktor.vajc@fs.cvut.cz

**e-mail: martin.dostal@fs.cvut.cz
}

of these correlations and use them later to compare our experimental results with values they predict.

Rohsenow [2] correlation

$$
\mathrm{Nu}_{\mathrm{b}}=\frac{1}{C_{\mathrm{sf}}} \operatorname{Re}_{\mathrm{b}}{ }^{2 / 3} \operatorname{Pr}_{1}^{1-m}
$$

was derived already in 1952 and still probably is the most used and validated correlation for saturated nucleate pool boiling. Coefficient $C_{\text {sf }}$ depends on combination of boiling liquid and material of heating surface, e.g., for water - stainless steel $C_{\mathrm{sf}}=0.013$, for water-brass $C_{\mathrm{sf}}=0.006$ and for ethanol-chrome $C_{\mathrm{sf}}=0.0027$. Exponent $m=1.7$ for various liquids boiling on clear heating surfaces except for water, for which $m=1.0$. Bubble Nusselt number $\mathrm{Nu}_{\mathrm{b}}=\alpha D_{\mathrm{L}} / \lambda_{1}$, Prandtl number of liquid $\operatorname{Pr}_{1}=\mu_{1} / a_{1}$, bubble Reynolds number

$$
\operatorname{Re}_{\mathrm{b}}=\frac{q D_{\mathrm{L}}}{\mu_{\mathrm{l}} \Delta h_{\mathrm{lg}}}
$$

and Laplace's bubble diameter.

$$
D_{\mathrm{L}}=\sqrt{\frac{\sigma}{g\left(\varrho_{1}-\varrho_{\mathrm{g}}\right)}} .
$$

Correlation (1) is dimensionless and was originally based on experimental datasets obtained for pressure ranges from $101 \mathrm{kPa}$ to $17 \mathrm{MPa}$, although it was successfully applied for pressures outside this range. For example McGillis et al. [3] used this correlation even for vacuum of $16 \mathrm{kPa}$.

Stephan and Abdelsalam [4] correlations use appropriate sets of complexes for different boiling fluids. For water (assuming that contact angle between the liquid-vapor in- 
terface measured through the liquid $\beta_{\mathrm{c}}=45^{\circ}$ ) they derived

$$
\begin{aligned}
\mathrm{Nu}_{\mathrm{b}}=0.246 & \cdot 10^{7}\left(\frac{q D_{\mathrm{b}}}{\lambda_{\mathrm{l}} T_{\mathrm{sat}}}\right)^{0.673}\left(\frac{\Delta h_{\mathrm{lg}} D_{\mathrm{b}}^{2}}{a_{1}^{2}}\right)^{-1.58} . \\
& \cdot\left(\frac{c_{p, 1} T_{\mathrm{sat}} D_{\mathrm{b}}^{2}}{a_{1}^{2}}\right)^{1.26}\left(\frac{\varrho_{1}-\varrho_{\mathrm{g}}}{\varrho_{1}}\right)^{5.22} .
\end{aligned}
$$

Bubble departure diameter should be obtained from Fritz [5] correlation

$$
D_{\mathrm{b}}=C_{\mathrm{d}} \beta_{\mathrm{c}} D_{\mathrm{L}},
$$

where value of coefficient $C_{\mathrm{d}}=0.0208$ is usually taken and $D_{\mathrm{L}}$ is calculated with (3).

Nishikawa [6] correlation respects roughness of the heating surface. Jones et al. [7] present it in modified dimensional form

$$
\alpha=\frac{31.4 p_{\mathrm{cr}}^{0.2}}{M_{\mathrm{m}}^{0.1} T_{\mathrm{cr}}^{0.9}}\left(8 \frac{R a}{R a_{0}}\right)^{0.2\left(1-p_{\mathrm{red}}\right)} \frac{p_{\mathrm{red}}^{0.23} q^{0.8}}{\left(1-0.99 p_{\mathrm{red}}\right)^{0.9}} .
$$

Reference roughness $R a_{0}=0.4 \mu \mathrm{m}, M_{\mathrm{m}}$ needs to be in $\mathrm{kg} \mathrm{kmol}^{-1}, p_{\mathrm{cr}}$ in $\mathrm{Pa}$ and $T_{\mathrm{cr}}$ in kelvins.

Mostinski [8] arrived at the dimensional correlation

$$
\alpha=0.00417 p_{\mathrm{cr}}^{0.69} q^{0.7} F_{p} .
$$

According to Mostinski, pressure correction factor should be calculated using

$$
F_{p}=1.8 p_{\text {red }}^{0.17}+4 p_{\text {red }}^{1.2}+10 p_{\text {red }}^{10} .
$$

Yagov [9] derived correlation based on his approximative model of nucleate pool boiling

$$
\begin{aligned}
q=3.43 \cdot 10^{-4} & \frac{\lambda^{2} \Delta T^{3}}{v_{1} \sigma T_{\mathrm{sat}}}\left(1+\frac{\Delta h_{\mathrm{lg}} \Delta T M_{\mathrm{m}}}{2 R_{\mathrm{m}} T_{\mathrm{sat}}^{2}}\right) . \\
& \cdot\left(1+\sqrt{1+800 C_{\mathrm{b}}}+400 C_{\mathrm{b}}\right) .
\end{aligned}
$$

Dimensionless boiling parameter

$$
C_{\mathrm{b}}=\frac{\Delta h_{\mathrm{lg}}\left(\varrho_{\mathrm{g}} v_{1}\right)^{3 / 2}}{\sigma\left(\lambda_{1} T_{\mathrm{sat}}\right)^{1 / 2}} .
$$

$T_{\text {sat }}$ in (9) and (10) should be in kelvins. In order to use equation (9), relation

$$
\Delta T=q / \alpha
$$

based on Newton's cooling law was put into (9) and $\alpha$ was calculated iteratively.

\section{Experimental apparatus and procedure}

\subsection{The apparatus}

Experiments were performed on the apparatus shown in Fig. 1. Apparatus was opened, which means, that vapor could escape into ambient air and water had to be refilled after some time. Experiments were thus executed under atmospheric pressures, which was measured with pressure web sensor Comet T7510.

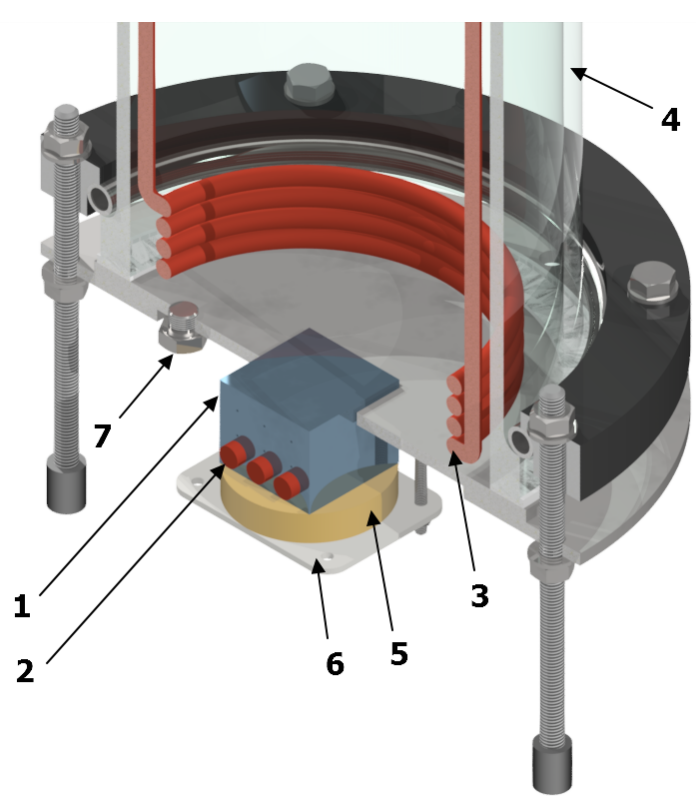

Fig. 1. Apparatus assembly; 1 Heated block, 2 Heating cartridges, 3 Auxiliary heater, 4 Glass cylinder, 5 Isolating pad, 6 Assembly pad, 7 Plug

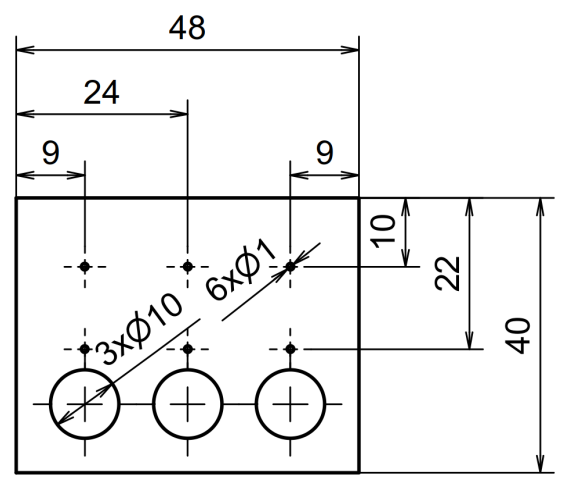

Fig. 2. Drawing of the heated block

Cylinder made of borosilicate glass with internal diameter of $200 \mathrm{~mm}$ stands on stainless-steel bottom with an opening for square $48 \times 48 \mathrm{~mm}$ stainless-steel heated block. Stainless-steel components are made of 1.4301 according to ČSN EN 10 0027-2. Top side of the block serves as a heating surface for liquid in the cylinder. The block stands on isolating pad made of glass and is heated by three horizontally-placed cartridge heaters with diameter of $10 \mathrm{~mm}$, length of $60 \mathrm{~mm}$ and nominal power of one cartridge $400 \mathrm{~W}$. We also used auxiliary heating spiral made of Inconol-800 with nominal power of $3 \mathrm{~kW}$. Power supplied to cartridges and spiral was set with variacs.

Gap between the block and the bottom is sealed with a combination of epoxy resin Kittfort Epoxy 1200 and Versachem silicone, which should withstand temperatures up to $320^{\circ} \mathrm{C}$.

We tried to perform some experiments without any isolation of both block and glass cylinder. However subcoolings of boiling liquid were too high, so we wrapped the cylinder and the block into isolation made of glass wool. 


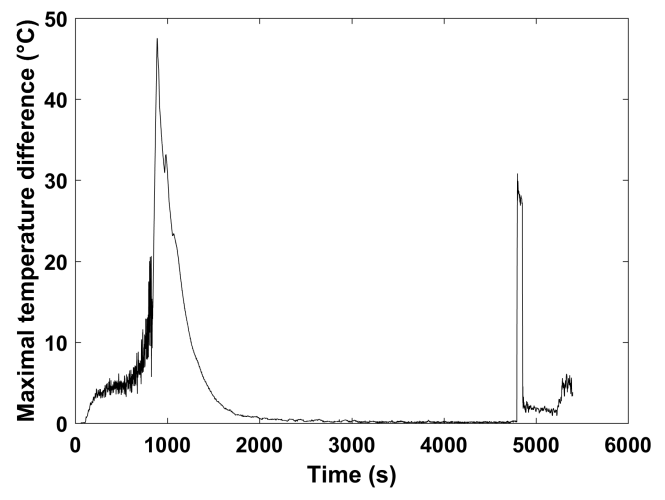

Fig. 3. Development of maximal temperature difference in time

There are six $25 \mathrm{~mm}$ long horizontal holes of $1 \mathrm{~mm}$ diameter drilled into the heated block as is shown in Figure 2. These holes were aligned in two horizontal lines. Six thermocouples - usually some combination of sheathed OMEGA TMQSS-040(U)-6 and bare-wire OMEGA 5TC-TT-K-36-72 - were inserted into the holes to measure temperatures inside the block. Tips of barewire thermocouples were coated with OB-600 chemicalset cement. Temperature of the liquid was measured with thermocouple probe TJ36-CASS-116(U)-12. Tip of the probe is placed about $15 \mathrm{~mm}$ above the heating surface.

Reference point with temperature $0{ }^{\circ} \mathrm{C}$ for cold ends of thermocouples was created with ice-point calibration reference chamber OMEGA TRCIII-A. Calibration probes TRP-K-36 and TRP-T-36 were inserted into its six cylindrical chambers. External module JanasCard AD24USB was used to convert signals from thermocouples and bring them to PC input.

\subsection{Principle of measurement}

We use six temperatures measured by thermocouples inside the heated block to calculate average temperatures in both lines. Then we calculate:

- temperature gradient inside the block;

- temperature of the heating surface $T_{\mathrm{w}}$;

- heat flux $q$ assuming, that thermal conductivity of the block $\lambda=15 \mathrm{~W} \mathrm{~m}^{-1} \mathrm{~K}^{-1}$.

We than use measured temperature of the liquid bulk $T_{1}$ to determine superheat

$$
\Delta T=T_{\mathrm{w}}-T_{1}
$$

Finally we obtain desired heat-transfer coefficient from Newton's cooling law, i.e., $\alpha=q / \Delta T$.

\subsection{Data evaluation}

Sampling period of AD24USB was set to one second. During measurements we found out, that time needed for reaching a steady state, in which temperatures are stabilized, is pretty long. In order to find sufficiently-stable regions, we used arbitrary time step $\Delta t=60 \mathrm{~s}$ and waited until differences of all temperatures measured at time $t_{1}$
Table 1. Table of results

\begin{tabular}{lrccccc}
\hline $\begin{array}{c}\text { No. } \\
(-)\end{array}$ & $\begin{array}{c}\text { Points } \\
(-)\end{array}$ & $\begin{array}{c}T_{\mathrm{w}} \\
\left({ }^{\circ} \mathrm{C}\right)\end{array}$ & $\begin{array}{c}T_{1} \\
\left({ }^{\circ} \mathrm{C}\right)\end{array}$ & $\begin{array}{c}T_{\mathrm{sat}} \\
\left({ }^{\circ} \mathrm{C}\right)\end{array}$ & $\begin{array}{c}q \\
\left(\mathrm{~W} \mathrm{~m}^{-2}\right)\end{array}$ & $\begin{array}{c}\alpha \\
\left(\mathrm{W} \mathrm{m}^{-2} \mathrm{~K}^{-1}\right)\end{array}$ \\
\hline 1 & 289 & 108.5 & 98.7 & 99.2 & 81080 & 8231 \\
2 & 127 & 106.8 & 98.4 & 99.2 & 81041 & 9628 \\
3 & 1792 & 109.3 & 98.9 & 99.1 & 82234 & 7866 \\
4 & 2114 & 109.5 & 98.7 & 99.1 & 82027 & 7564 \\
5 & 90 & 106.9 & 98.7 & 99.4 & 99422 & 12164 \\
6 & 690 & 106.8 & 98.8 & 99.4 & 92407 & 11567 \\
7 & 101 & 106.7 & 98.8 & 99.4 & 90812 & 11483 \\
8 & 168 & 107.0 & 98.4 & 99.3 & 93343 & 10964 \\
\hline
\end{tabular}

and at time $t_{2}=t_{1}-\Delta t$ fell and stayed below an arbitrary limit value - typically of about $0.3{ }^{\circ} \mathrm{C}$. Common change of maximal temperature difference with time can be seen in Figure 3. Peak at time of about $3700 \mathrm{~s}$ is caused by a change of power supplied to heaters. Region between 1650 and $3700 \mathrm{~s}$ in Figure 3 was considered to be stable.

Average temperatures in both rows of the heated block were calculated simply as an arithmetic mean of temperatures in corresponding row. Temperature difference between both lines lied typically between 50 and $70{ }^{\circ} \mathrm{C}$.

All needed thermophysical properties of water were obtained from MATLAB script X Steam, which can be downloaded from www.X-eng.com.

\section{Results}

Results from eight chosen testing measurements are presented in Table 1. Values of $\alpha$ calculated with correlations mentioned in section 2 are in Table 2. Correlations were used for heat fluxes $q$ from 80 to $100 \mathrm{~kW} \mathrm{~m}^{-2}$. For calculations we assumed pressure $p=98.8 \mathrm{kPa}$, which is an average pressure calculated from saturation pressures corresponding to saturation temperatures given in Table 1 .

For Nishikawa correlation (6) roughness of the heating surface $R a=0.4 \mu \mathrm{m}$ was used. This value is based on stylus-method measurement on stationary surface-measuring station Mahr Marsurf XR 20.

Graphical comparison of measured data and trends of correlations mentioned in section 2 are in Figure 4. One can clearly see, that the Rohsenow correlation (1) predicts the highest heat-transfer coefficients.

\section{Discussion}

It is obvious from Figure 4, that three bottom left points do not copy trends predicted with correlations and that they are scattered, while for five remaining points higher 
Table 2. Heat-transfer coefficient $\alpha\left(\mathrm{W} \mathrm{m}^{-2} \mathrm{~K}^{-1}\right)$ estimated from correlations for different heat fluxes $q\left(\mathrm{~kW} \mathrm{~m}^{-2}\right)$

\begin{tabular}{lccccl}
\hline Correlation & $q=80$ & 85 & 90 & 95 & $100 \mathrm{~kW} \mathrm{~m}^{-2}$ \\
\hline Rohsenow & 9572 & 9966 & 10353 & 10733 & 11107 \\
St. \& Ab. & 7483 & 7794 & 8100 & 8400 & 8695 \\
Nishikawa & 7480 & 7852 & 8219 & 8582 & 8942 \\
Mostinski & 8196 & 8552 & 8901 & 9244 & 9582 \\
Yagov & 6937 & 7224 & 7505 & 7781 & 8052 \\
\hline
\end{tabular}

coefficients were measured compared to those, that were correlated, but the trend more or less corresponds to those obtained with correlations. Several possible explanations of such results offer themselves. From Table 1 one can see, that liquid temperature $T_{1}$ is lower than saturation temperature $T_{\text {sat }}$ for all measurements. This means, that for these measurements boiling was subcooled in average by $0.6^{\circ} \mathrm{C}$. Nucleate-pool-boiling correlations are usually (although not always) created precisely for saturated boiling. For the same heat flux larger subcooling should reduce heat-transfer coefficient, which is however not satisfied for dataset in Table 1.

Another problem (which cannot be deduced from Table 1) is, that temperatures measured by thermocouples in one horizontal row differed in a relatively large extent, especially for the thermocouple line closer to heating cartridges. These differences were of about 3 to $4{ }^{\circ} \mathrm{C}$ for the upper line, but of about 6 to $8^{\circ} \mathrm{C}$ for the lower line. Such a variation might indicate unwanted heat conduction in horizontal direction, which should be eliminated, since the measurement method described in section 3.2 is based on the assumption of one-dimensional vertical heat conduction.

Heat-transfer coefficients were measured for relatively high heat fluxes due to inability to reach stable and sufficiently-intense bubble nucleation at lower $q$. Auxiliary heating spiral was not separated from the liquid bulk above the heating surface, but careful adjustments of supplied electric power were made to suppress bubble nucleation on the spiral as much as possible. We could not completely prevent bubble nucleation on the spiral, because sufficiently-stable temperature of the liquid bulk $T_{1}$ would then not be reached. Power supplied to the spiral was comparable with power supplied to heating cartridges.

Heat fluxes $q$ were calculated from the temperature gradients in the heated block, which means, that they are based on average temperatures measured by thermocouples. Due to possible heat conduction in horizontal direction actual reached heat fluxes could be different from those, that were calculated. It would be useful to compare heat fluxes obtained with this method and those measured for example with wattmeters connected to supply wiring.

For presented measurements thermocouples were not calibrated, but we verified, that measured temperatures of

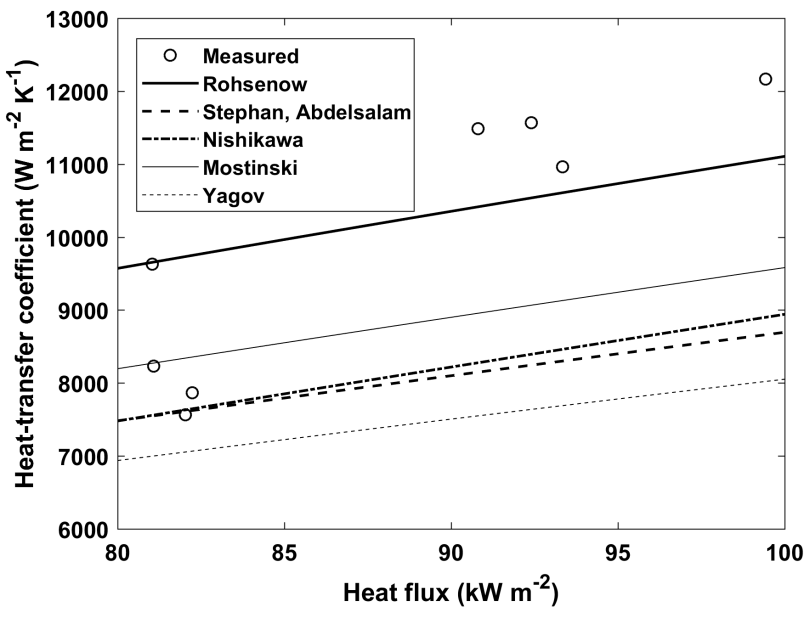

Fig. 4. Comparison of measured heat-transfer coefficients and trends predicted by correlations

the liquid intensively boiling on auxiliary heater agreed very well with tabulated saturation boiling temperatures corresponding to measured atmospheric pressures. Nevertheless we want to calibrate all measuring thermocouples for future measurements. Temperature of the boiling liquid seemed constant in the whole bulk as we tried to change position of the thermocouple probe submerged in the boiling liquid. Epoxy used to seal the gap between the heated block and the bottom of the apparatus degraded after some time. It eventually unsticked from the bottom and sometimes drops of water seeped. When this happened, experiments were immediately stopped, apparatus was completely dismantled and assembled again.

We want to install new isolations for both the glass cylinder and the heated block. These isolations should be made of solid materials instead of currently-used pliable glass wool, which is also unsuitable for wet environments. Also vertical orientation of heating cartridges will help to install the isolation more easily, improve temperature distribution inside the heated block and reduce heat losses. With horizontally-placed cartridges front and back faces of the block can not be isolated at all. We also want to separate auxiliary heating spiral from the liquid bulk above the heating surface.

During measurements with tap water limescale deposited on the heating surface and created almost continuous thin coating. In view of the fact, that this coating might significantly influence boiling heat transfer, we decided to switch tap water for deionized water.

\section{Conclusion}

We have run several testing experiments on our apparatus, measured heat-transfer coefficients during nucleate pool boiling and compared obtained results with some verified nucleate-pool-boiling correlations.

On the one hand some measured points evince trends comparable to values calculated with correlations, on the other hand four heat-transfer coefficients from approximately 7.5 up to $9.6 \mathrm{~kW} \mathrm{~m}^{-2} \mathrm{~K}^{-1}$ were obtained for almost constant heat flux of about $81.6 \mathrm{~kW} \mathrm{~m}^{-2}$. 
We observed temperature differences inside the heated block in horizontal direction, which need to be lowered in order to satisfy the fundamental assumption of one-dimensional heat conduction in the heated block.

We are planning to implement adjustments mentioned in section 5 Possible not-mentioned improvements and modifications will follow as we proceed with our measurements.

This work was supported by the Ministry of Education, Youth and Sports of the Czech Republic under OP RDE grant number CZ.02.1.01/0.0/0.0/16_019/0000753 "Research centre for low-carbon energy technologies" and by the Grant Agency of the Czech Technical University in Prague, grant No. SGS18/129.

\section{Nomenclature}

a thermal diffusivity

$c_{p} \quad$ isobaric specific-heat capacity

$C_{\mathrm{b}} \quad$ boiling parameter in (9)

$C_{\mathrm{d}} \quad$ coefficient in (5)

$C_{\text {sf }} \quad$ liquid-surface coefficient in (1)

$D_{\text {b }} \quad$ bubble departure diameter

$D_{\mathrm{L}} \quad$ Laplace's diameter

$F_{p} \quad$ pressure-correction factor in (7)

$g$ gravitational acceleration

$m$ exponent in (1)

$M_{\mathrm{m}} \quad$ molar mass

$\mathrm{Nu}$ Nusselt number

$p$ pressure

Pr Prandtl number

$q \quad$ heat flux

$R_{\mathrm{m}} \quad$ universal gas constant

$R a \quad$ surface roughness

$R a_{0} \quad$ reference roughness in (6)

Re Reynolds number

$t$ time

$T$ temperature

$\begin{array}{lll}\alpha & \text { heat-transfer coefficient } & \left.(\mathrm{W} \mathrm{m})^{-2} \mathrm{~K}^{-1}\right) \\ \beta_{\mathrm{c}} & \text { contact angle } & \left({ }^{\circ}\right) \\ \Delta t & \text { time difference } & (\mathrm{s}) \\ \Delta T & \text { superheat } & (\mathrm{K}) \\ \Delta h_{\mathrm{lg}} & \text { specific latent heat of vaporization } & \left(\mathrm{J} \mathrm{kg}^{-1}\right) \\ \lambda & \text { thermal conductivity } & \left(\mathrm{W} \mathrm{m}^{-1} \mathrm{~K}^{-1}\right) \\ \mu & \text { dynamic viscosity } & \left(\mathrm{Pa} \mathrm{s}^{2}\right) \\ v & \text { kinematic viscosity } & \left(\mathrm{m}^{2} \mathrm{~s}^{-1}\right) \\ \varrho & \text { density } & \left(\mathrm{kg} \mathrm{m}^{-3}\right) \\ \sigma & \text { surface tension } & \left(\mathrm{N} \mathrm{m}^{-1}\right)\end{array}$

Subscripts:

b related to bubble

cr critical property

g related to vapor phase

1 related to liquid phase

red reduced

sat at saturation state

w related to the heating surface

\section{References}

[1] V. Vajc, Master's thesis, Czech Technical University, Prague, Czech Republic (2017)

[2] W.M. Rohsenow, Tech. rep., MIT Division of Industrial Cooporation (1952)

[3] W.R. McGillis, J.S. Fitch, W.R. Hamburgen, V.P. Carey, Tech. Rep. 91/7, Western Research Laboratory (1991)

[4] K. Stephan, M. Abdelsalam, Int. J. of Heat Mass Transf. 23, 73 (1980)

[5] W. Fritz, Phys. Z. 36, 379 (1935)

[6] K. Nishikawa, Y. Fujita, H. Ohta, S. Hidaka, Proc. Seventh Int. Heat Transf. Conf. 4, 61 (1982)

[7] B.J. Jones, J.P. McHale, S. Garimella, J. of Heat Transf. 131, 1 (2009)

[8] I.L. Mostinski, Teploenergetika 10, 66 (1963)

[9] V.V. Yagov, Heat Mass Transf. 45, 881 (2009) 